\title{
The Relationship between Haemodialysis Procedures and Interleukin-6 Levels in Regular Hemodialysis Patients in Haji Adam Malik Central General Hospital
}

\author{
Achmad Tri Wibowo', Alwi Thamrin Nasution, Radar Radius Tarigan², \\ Putri C. Eyanoer ${ }^{3}$ \\ ${ }^{1}$ Department of Internal Medicine, Faculty of Medicine, Universitas Sumatera Utara, Medan, Indonesia \\ ${ }^{2}$ Division of Nephrology and Hypertension, Department of Internal Medicine, Faculty of Medicine, Universitas \\ Sumatera Utara, Medan, Indonesia \\ ${ }^{3}$ Department of Community and Preventive Medicine, Faculty of Medicine, Universitas Sumatera Utara, Medan, \\ Indonesia \\ Corresponding Author: Achmad Tri Wibowo
}

\begin{abstract}
Introduction: Chronic kidney disease (CKD) is kidney damage characterized by the presence of protein in the urine or a decrease in the glomerular filtration rate (GFR). CKD is a global problem throughout the world, including Indonesia, which requires special attention. IL-6 is known to play a role in regulating hemostatic functions, including glucose metabolism, the hypothalamus-pituitary-adrenal (HPA) axis, influencing mood, fatigue, depression, and hematopoiesis. As an inflammatory cytokine, IL-6 is an inflammatory mediator that most plays a role in various conditions, such as infection, autoimmune disease, and cancer. In CKD patients undergoing dialysis (HD), elevated serum IL-6 levels beginning from the start of the treatment is a strong predictor of mortality. The study aimed to determine the association between hemodialysis procedures and interleukin-6 levels in regular hemodialysis CKD patients in Haji Adam Malik Central General Hospital.

Methods: This is an analytical study with a cross-sectional design. A total of 20 study subjects met the inclusion criteria and exclusion criteria, underwent history taking, physical examination, anthropometry, and laboratory examination to measure hemoglobin, creatinine, albumin, and IL-6 levels. Data analysis was performed using SPSS.
\end{abstract}

Results: The median level of IL-6 before hemodialysis was $10.39 \mathrm{pg} / \mathrm{mL}$ with the lowest level and the highest level being $1.50-74.79$ $\mathrm{pg} / \mathrm{mL}$, the median level of IL-6 after hemodialysis was $29.13 \mathrm{pg} / \mathrm{mL}$ with the lowest level and the lowest level. the highest is 2.11 $316.20 \mathrm{pg} / \mathrm{mL}$. Based on the results of the analysis, the levels of IL-6 after hemodialysis were higher than the levels of IL- 6 before hemodialysis, there was a statistically significant relationship between regular hemodialysis and interleukin-6 levels before and after in patients with kidney disease.

Conclusion: Regular hemodialysis and interleukin-6 levels have a statistically significant relationship before and after hemodialysis in CKD patients.

Keywords: Chronic kidney disease; haemodialysis; interleukin-6

\section{INTRODUCTION}

Chronic kidney disease (CKD) is kidney damage characterized by the presence of protein in the urine or a decrease in the glomerular filtration rate (GFR). CKD is a global problem throughout the world, including Indonesia, which requires special attention. CKD is a major health problem with a poor prognosis, leading to high morbidity and mortality 
rates. In addition, PGK also requires highcost management. Purcell et al. reported that the estimated incidence of CKD worldwide in 2017 was 1.2 million cases with a $41.5 \%$ increase in mortality from 1990 to 2017. [1]

In patients with CKD, there is a recurrent and chronic inflammatory process. However, to date, no consensus was made on the assessment of the degree of inflammation in CKD patients, including those on dialysis. Thus, in recent years, various studies have begun to explore the role of various cytokines in CKD patients. Based on previous studies, one of the cytokines known to play a role in the inflammatory process in CKD patients is interleukin (IL)-6. [2]

IL-6 is known to play a role in regulating hemostatic functions, including glucose metabolism, the hypothalamuspituitary-adrenal (HPA) axis, influencing mood, fatigue, depression, and hematopoiesis. As an inflammatory cytokine, IL-6 is an inflammatory mediator that most plays a role in various conditions, such as infection, autoimmune disease, and cancer. Both clinical and experimental trials have shown that IL-6 plays a role in kidney damage. IL-6 levels increased in CKD patients, due to impaired excretion in kidney damage and an increase in IL-6 mRNA levels in mononuclear cells in the peripheral blood circulation. Increased levels of IL-6 in the systemic circulation indicate persistent and episodic inflammation involving comorbidities, genetic factors, obesity, metabolic disorders, infections, and immunological processes. In CKD patients undergoing dialysis (HD), elevated serum IL-6 levels beginning from the start of the treatment is a strong predictor of mortality. [3]

The pathogenesis of the chronic inflammatory process associated with uremia is currently unknown, but various factors related to the dialysis procedure may trigger a persistent inflammatory response. Examples of dialysis procedure factors that can influence are poor membrane biocompatibility of the dialyzer machine, contamination, type of vascular access, and other factors. [4] The study aimed to determine the association between hemodialysis procedures and interleukin-6 levels in regular hemodialysis CKD patients in Haji Adam Malik Central General Hospital.

\section{MATERIALS \& METHODS}

This study is an analytical study with a cross-sectional design. The study was conducted at the Haji Adam Malik Central General Hospital (RSUP) Medan after obtaining approval from the Health Research Ethics Commission of USU Medical Faculty / H. Adam Malik Hospital Medan starting from August 2020. A total of 20 study subjects met the inclusion criteria and exclusion criteria. The study inclusion criteria were as follows: chronic kidney disease patients undergoing regular hemodialysis ( $\geq 3$ years), at least 18 years old, and with informed consent to participate in the study. Data were obtained from medical record data including patient identity, duration of hemodialysis, and history of CKD. Subjects were asked to fill in questionnaires and underwent history taking, physical examination, anthropometry, and laboratory examination to measure hemoglobin, creatinine, albumin, and IL-6 levels.

\section{Statistical Analysis}

Data analysis was performed using the Statistical Package for the Social Sciences (SPSS) 24.0 software. Numerical variables is presented in the form of mean \pm standard deviation if the data is normally distributed, and in median (minimum value - maximum value) if the data is not normally distributed. Categorical variables were presented as percentages.

\section{RESULT}

This study included 20 research subjects of sepsis patients at the Haji Adam Malik Central General Hospital Medan in 2020 who had met the inclusion and exclusion criteria. The average age of the 
research subjects was 45 years, the majority of the research subjects were male (13 people $[65.0 \%])$ and women (7 people [35.0\%]). 11 subjects underwent hemodialysis for $<1$ year $(55.0 \%), 7$ subjects were $>5$ years $(35.0 \%)$, and 2 subjects for $1-5$ years (10.0\%). All study subjects were not obese and had no history of infection. The characteristics of the subjects are presented in (Table 1).

Table 1. Subject Characteristics

\begin{tabular}{|c|l|l|}
\hline Characteristics & $\mathbf{n}=\mathbf{2 0}$ & $\mathbf{\%}$ \\
\hline Age, (years) mean $\mathbf{S D}$ & $\mathbf{4 5 , 4 5} \pm \mathbf{1 5 , 5 4}$ & - \\
\hline Sex & & \\
\hline Male & 13 & 65,0 \\
\hline Female & 7 & 35,0 \\
\hline Hemodialysis duration & & \\
\hline <1 year & 11 & 55,0 \\
\hline 1-5 years & 2 & 10,0 \\
\hline >5 years & 7 & 35,0 \\
\hline Obesity & & \\
\hline Yes & 0 & 00,0 \\
\hline No & 20 & 100,0 \\
\hline Infection & & \\
\hline Yes & 0 & 00,0 \\
\hline No & 20 & 100,0 \\
\hline
\end{tabular}

The median level of IL- 6 before hemodialysis was $10.39 \mathrm{pg} / \mathrm{mL}$ with the lowest level and the highest level being 1.50 - $74.79 \mathrm{pg} / \mathrm{mL}$, the median level of IL-6 after hemodialysis was $29.13 \mathrm{pg} / \mathrm{mL}$ with the lowest level and the lowest level. the highest is $2.11-316.20 \mathrm{pg} / \mathrm{mL}$. Based on the results of the analysis, the levels of IL-6 after hemodialysis were higher than the levels of IL- 6 before hemodialysis, there is a statistically significant relationship between regular hemodialysis and interleukin-6 levels before and after in patients with kidney disease (Table 2).

Table 5.2 The relationship between hemodialysis and interleukin-6 levels in patients with chronic kidney disease on regular hemodialysis

\begin{tabular}{|l|l|l|}
\hline Variable & Level $(\mathrm{pg} / \mathrm{mL})$ & p value
\end{tabular}

\begin{tabular}{|l|l|l}
\hline IL-6 Pre-hemodialysis & $10,39(1,50-74,79)$ & $0,006^{*}$
\end{tabular}
IL-6 Post-hemodialysis $29,13(2,11-316,20)$

Numerical data is presented in the form of mean \pm standard deviation if the data is normally distributed, numerical data is presented in the form of median (minimum value - maximum value) if the data is not normally distributed. *Wilcoxon test, the data is significant if $p$ value $<0.05$.

\section{DISCUSSION}

In this study, there was a statistically significant relationship between regular hemodialysis and interleukin-6 levels before and after dialysis in kidney disease patients ( $\mathrm{p}$ value $=0.006$ ), where serum IL-6 levels after hemodialysis increased significantly (IL-6 before HD $10.39 \mathrm{pg} / \mathrm{mL}$ and after HD $29.13 \mathrm{pg} / \mathrm{mL}$ ). The results of this study are in line with a study by Zhang which reported that there was an increase in IL-6 in post-HD patients.52 Likewise, the study by Zahed et al. on hemodialysis patients who experienced metabolic acidosis, the average serum IL-6 level was $6.036 \mathrm{pg} / \mathrm{ml}$ with a mean serum IL-6 level of 6.036 $\mathrm{pg} / \mathrm{ml}$, with the duration of hemodialysis for 24.8 months. [5] Similarly, Barreto et al. reported that the average IL-6 level of hemodialysis patients in their study was $5.25 \pm 7.89 \mathrm{pg} / \mathrm{mL}$ and concluded that there was a strong relationship between increased IL-6 levels in CKD patients on HD and progression to stage $\mathrm{V}$ CKD.43 Recent studies have shown that higher serum IL-6 levels are associated with mortality in clinically stable HD patients. [6]

Both hemodialysis and peritoneal dialysis resulted in increased blood mononuclear cell IL-6 mRNA expression and plasma IL-6 levels. [7] Circulating IL-6 levels increased after hemodialysis, providing evidence of a delayed inflammatory response that is induced hemodialysis. [8] Several factors that contribute to the formation of IL- 6 and/or enhance the inflammatory effect of IL-6 due to hemodialysis are still hypothesized and uncertain, but the use of bioincompatible membranes and nonsterile dialysates could be a triggering factor. [9]

Kamimura et al. tested the levels of IL-6 in CKD patients on HD compared to IL-6 in healthy people, in which they reported that CRP and serum IL-6 levels of hemodialysis patients were significantly higher than the control group (11 healthy people), these results are in accordance with previous studies that demonstrated an overproduction of cytokines by monocytes in patients with uremic disorders. [10] Hemodialysis activates cytokines that induce protein catabolism and trigger apoptosis. In HD 
patients, inflammatory mediators such as IL-1, IL-6, and tumor necrosis factor alpha, can lead to the synthesis and release of Creactive protein (CRP), decreased albumin, prealbumin, and increased homocysteine and endothelin-I. All of these factors contribute to the development of atherosclerotic complications and death in HD patients, thus IL-6 can be considered as a prognostic marker in such patients. [5]

A study by Barreto et al found that plasma levels of IL-6 were found to be significantly higher in terminally ill patients with acute renal failure who died than in those who survived (regardless of sepsis status). In elderly and CKD patients on HD, plasma IL-6 levels have been shown to be better at predicting mortality than IL- $1 \beta$, TNF-, CRP or albumin levels. IL-6 levels tend to increase as CKD progresses to stage V CKG. [11]

\section{CONCLUSION}

Regular haemodialysis and interleukin-6 levels have a statistically significant relationship before and after haemodialysis in CKD patients.

Acknowledgement: None

\section{Conflict of Interest: None}

\section{Source of Funding: None}

Ethical Approval: Approved

\section{REFERENCES}

1. GBD Chronic Kidney Disease Collaboration. Global, regional, and national burden of chronic kidney disease, 1990-2017: a systematic analysis for the Global Burden of Disease Study 2017. The Lancet. 2020;395:709 - 733 . doi: 10.1016/S0140-6736(20)30045-3.

2. Alwahaibi NY, et al. Serum levels of TNF- $\alpha$, IL-6 and IL-10 in haemodialisis and renal transplant patients and in healthy subjects. Port J Nephrol Hypert. 2016;30(2):194-198.
3. SA Jones, et al. Interleukin-6 in renal disease and therapy. Nephrol Dial Transplant. 2015;30: 564-574. doi: 10.1093/ndt/gfu23

4. Barreto DV, et al. Plasma interleukin-6 is independently associated with mortality in both hemodialisis and predialisis patients with chronic kidney disease. Kidney International. 2010; 77:550-556

5. Zahed N, Chehrazi S. The evaluation of the relationship between serum levels of Interleukin-6 and Interleukin-10 and metabolic acidosis in hemodialysis patients. Saudi Journal of Kidney Diseases and Transplantation. 2017;28(1):23. doi: 10.4103/13192442.198106.

6. Beberashvili I, Sinuani I, Azar A, Yasur H, Shapiro G, Feldman L et al. IL-6 Levels, Nutritional Status, and Mortality in Prevalent Hemodialysis Patients. Clinical Journal of the American Society of Nephrology. 2011;6(9):2253-2263. doi: 10.2215/CJN.01770211.

7. Takahashi T, Kubota M, Nakamura T, Ebihara I, Koide H. Interleukin-6 gene expression in peripheral blood mononuclear cells from patients undergoing hemodialysis or continuous ambulatory peritoneal dialysis. Renal Failure. 2000;22(3):345-354. doi: 10.1081/JDI-100100878.

8. Caglar K, Peng Y, Pupim L, Flakoll P, Levenhagen D, Hakim $\mathrm{R}$ et al. Inflammatory signals associated with hemodialysis. Kidney International. 2002;62(4):1408-1416. doi: 10.1111/j.1523-1755.2002.kid556.x.

9. Stenvinkel P, Alvestrand A. Review Articles: Inflammation in End- stage Renal Disease: Sources, Consequences, and Therapy. Seminars in Dialysis. 2002;15(5):329-337. doi: 10.1046/j.1525-139X.2002.00083.x.

10. Kamimura M, Draibe S, Dalboni M, Cendoroglo M, Avesani C, Manfredi S et al. Serum and cellular interleukin-6 in haemodialysis patients: relationship with energy expenditure. Nephrology 
Achmad Tri Wibowo et.al. The relationship between haemodialysis procedures and interleukin-6 levels in regular hemodialysis patients in Haji Adam Malik Central general hospital.

\section{Dialysis}

2007;22(3):839-844.

10.1093/ndt/gfl705.

11. Barreto D, Barreto F, Liabeuf $S$, Temmar M, Lemke H, Tribouilloy $\mathrm{C}$ et al. Plasma interleukin-6 is independently associated with mortality in both hemodialysis and pre-dialysis patients with chronic kidney disease. Kidney International. 2010;77(6):550-556. doi: 10.1038/ki.2009.503.

Transplantation. doi: How to cite this article: Wibowo AT, Nasution AT, Tarigan RR et.al. The relationship between haemodialysis procedures and interleukin-6 levels in regular hemodialysis patients in Haji Adam Malik Central general hospital. International Journal of Research and Review. 2021; 8(10): 418-422. DOI: https://doi.org/10. 52403/ijrr.20211056 